\title{
Correction to: O-Ti (Oxygen-Titanium)
}

\section{Hiroaki Okamoto ${ }^{1}$}

Published online: 16 December 2020

(c) ASM International 2020

\section{Correction to:}

J. Phase Equilib. Diffus. 22, 515 (2001) https://doi.org/10.1361/105497101770338635

Due to a conversion error the original article was incomplete. The original article has been revised and it is now complete.
Publisher's Note Springer Nature remains neutral with regard to jurisdictional claims in published maps and institutional affiliations.

The original article can be found online at https:// doi.org/10.1361/105497101770338635.

$\triangle$ Hiroaki Okamoto

hokamoto@re.commufa.jp

1 Nagoya, Japan 